\title{
FINANÇAS PESSOAIS: UMA ANÁLISE DO COMPORTAMENTO DE ESTUDANTES DE CIÊNCIAS CONTÁBEIS
}

Personal finance: an analysis of Undergraduate Accounting students behavior

Mariana Ferreira Soares Marques
E-mail: marquesmariana93@gmail.com
Bacharel em Ciências Contábeis pela Universidade Federal de Minas Gerais.
https://orcid.org/0000-0002-5782-7792

Renata Turola Takamatsu

E-mail: rettakamatsu@gmail.com

Doutora em Controladoria e Contabilidade pela Faculdade de Economia, Administração e Contabilidade da Universidade de São Paulo; Mestre em Controladoria e Contabilidade pela Universidade de São Paulo;

Professora Adjunta no Departamento de Ciências Contábeis da Universidade Federal de Minas

Gerais.

https://orcid.org/0000-0002-0422-9895

Bruna Camargos Avelino

E-mail: bcavelino@gmail.com

Doutora em Controladoria e Contabilidade pela Faculdade de Economia, Administração e Contabilidade da Universidade de São Paulo; Mestre em Ciências Contábeis pela Universidade

Federal de Minas Gerais; Professora Adjunta no Departamento de Ciências Contábeis da Universidade Federal de Minas Gerais. Endereço para contato: Avenida Pres. Antônio Carlos, 6627, Pampulha, 31270-901, Belo Horizonte, Minas Gerais, Brasil. https://orcid.org/0000-0001-8958-8725

Artigo recebido em 04 de abril de 2018. Aceito em 08 de agosto de 2018. 


\section{Resumo}

A forma como as pessoas lidam com suas finanças pessoais é um tema cada vez mais relevante diante da complexidade dos meios de pagamento atuais, das formas de investimento existentes e da oferta do crédito restrita. Neste estudo propõe-se a analisar como os estudantes de Ciências Contábeis da Universidade Federal de Minas Gerais (UFMG) têm gerenciado suas finanças, a propensão ao endividamento ou à poupança desses indivíduos e a influência de aspectos comportamentais o autocontrole, a visão de curto prazo, a preferência por crédito e a propensão a planejar na gestão dos recursos. Foi realizado um estudo quantitativo, com a aplicação de questionários a 104 estudantes. Os resultados da pesquisa foram analisados por meio da análise fatorial, testes de correlação e de diferenças de médias. Observou-se, de forma geral, que os acadêmicos de Ciências Contábeis são altamente bancarizados e, em grande parte, possuem poupança e realizam depósitos regulares. Foi identificada uma maior propensão à poupança em alunos inseridos em famílias com renda superior a $R \$ 5.201,00$ e uma aversão a crédito de estudantes que poupam com a finalidade de prevenir emergências. A idade dos alunos não esteve correlacionada a nenhum padrão de comportamento.

Palavras-chave: Finanças Pessoais. Propensão ao endividamento. Propensão à poupança.

\section{Abstract}

The ways in which people deal with money is relevant given the complexity of current payment methods, existing types of investment and the credit supply restrictions. This research's aim was to assess how Undergraduate Accounting students manage their finances, their propensity for getting into debt, propensity to save and analyze how behavioral aspects (self-control, short-term thinking, preference for credit and propensity to plan) influence resources' management. We have applied a questionnaire to 104 students. We used principal component analysis, correlations and tests of differences between means. The results suggest that Accounting students are highly banked and, most of them have savings account and make periodic deposits. We have identified a higher Propensity to save money in families with incomes greater than $R \$ 5.201,00$ and debt aversion of students who save to prevent emergencies. Student's age was not correlated with any behavior pattern.

Keywords: Personal Finance. Propensity to save. Propensity for getting into debt.

\section{INTRODUÇÃO}

O comportamento do consumidor é foco de múltiplas áreas de estudo, tais como finanças, economia e marketing. Pesquisas sobre as decisões de consumo e estudos da gestão das despesas domésticas buscam compreender como o indivíduo aloca seus gastos, quais planejamentos realiza ou não, como efetua o controle do seu orçamento e, principalmente, como se torna poupador ou tomador de recursos. O perfil e as características que levam os indivíduos a figurarem em um dos dois grupos supracitados (poupador ou tomador) têm sido foco constante das pesquisas realizadas no âmbito acadêmico.

De acordo com o Instituto Brasileiro de Opinião Pública e Estatística (Ibope, 2012), apenas $31 \%$ da população brasileira declara fazer algum tipo de reserva de dinheiro, em contrapartida, a 
mesma pesquisa revelou que 37\% dos brasileiros afirmam ter algum tipo de dívida (parcelamento de compras, empréstimo ou financiamento). Entre as causas relacionadas ao nível de endividamento dos consumidores, pesquisas sugerem fatores como o consumo excessivo, a baixa renda, o desinteresse em poupar, o materialismo e a concessão de crédito (Katona, 1975; Slomp, 2008; Ponchio, 2006).

Para Katona (1975), a baixa renda, incapaz de fazer frente às despesas essenciais, e a alta renda, aliada a um gasto excessivo e ao desinteresse em economizar (em qualquer renda), são os fatores que explicam a inadimplência (gastos acima das receitas). Slomp (2008) identifica a concessão de crédito e o incentivo à compra como importantes fatores para o aumento do consumo e da inadimplência. Ponchio (2006), por sua vez, menciona que a faixa etária e o grau de escolaridade estariam diretamente relacionados ao nível de endividamento da população. Bortoluzzi, Boligon, Hollveg, e Medeiros (2015), ao avaliarem o comportamento de consumidores endividados e inadimplentes, detectaram que fatores relacionados ao descontrole e ao desconhecimento financeiro estariam fortemente relacionados à inadimplência.

Em relação às decisões de consumo possíveis, cada indivíduo busca enquadrar dentro do seu orçamento as necessidades de consumo individuais, empenhando-se em garantir a combinação que gere o maior bem-estar familiar (Lynch, Netemeyer, Spiller, \& Zammit 2010). A gestão das finanças domésticas é uma tarefa que auxilia os indivíduos na manutenção do orçamento e na formação de reservas. O gerenciamento das receitas e despesas, o orçamento mental e o rastreamento de contas bancárias serão os aspectos utilizados para analisar a gestão das finanças domésticas nesta pesquisa (Miotto, 2013).

A educação financeira é apontada por Borges (2010) como um fator que melhora a capacidade do indivíduo em tomar decisões financeiras. Dessa maneira, especificamente no ambiente universitário, espera-se que o nível de formação acerca de questões referentes a finanças pessoais seja mais amplo. Ainda, em se tratando de estudantes de Ciências Contábeis, espera-se uma compreensão mais aprofundada, diante das disciplinas realizadas no curso. Tendo em vista o que foi tratado, surge o seguinte questionamento: qual o comportamento financeiro de estudantes de Contabilidade da Universidade Federal de Minas Gerais (UFMG)? Neste estudo teve-se como objetivo, portanto, analisar as decisões de consumo e de poupança de alunos do Curso de Ciências Contábeis da UFMG.

O comportamento do consumidor é visto como capaz de gerar consequências pessoais e no agregado familiar, refletindo na economia, por meio, por exemplo, da adimplência ou da inadimplência de um segmento (Lynch et al., 2011). O acesso ao crédito tem sido facilitado, desde 2003, por medidas governamentais de redução de juros e de oferta de crédito. De acordo com Bortoluzzi et al. (2015), essa medida fez com que aumentasse o endividamento dos brasileiros de 2011 a 2014. Segundo os autores, esse aumento no volume de concessão de crédito preocupa pelo risco da inadimplência.

Este estudo se justifica pela importância de se confrontar o comportamento financeiro de estudantes de Ciências Contábeis da UFMG com a ocorrência de poupança ou endividamento, com vistas a suscitar a relevância da educação financeira e da gestão dos recursos. 


\section{REVISÃO TEÓRICA}

\subsection{EDUCAÇÃO FINANCEIRA}

A educação financeira, de acordo com o Banco Central do Brasil (Bacen, 2013), é um instrumento para promover o desenvolvimento econômico. Segundo o órgão, a qualidade das decisões financeiras influencia, no agregado, toda a economia. O órgão supracitado ainda revela que as atitudes comportamentais e os conhecimentos sobre gestão de finanças são instrumentos para que o cidadão desenvolva habilidades que melhorem sua qualidade de vida e de seus familiares.

Para a Organização para a Cooperação e Desenvolvimento Econômico (OCDE, 2004), "educação financeira sempre foi importante aos consumidores, para auxiliá-los a orçar e gerir a sua renda, a poupar e investir, e a evitar que se tornem vítimas de fraudes" (p. 223). A organização ressalta, também, a crescente relevância da educação financeira nos últimos anos, em razão do desenvolvimento dos mercados financeiros e das mudanças demográficas, econômicas e políticas.

No Brasil, o planejamento econômico-financeiro de longo prazo dos indivíduos foi comprometido pelo longo período de inflação, conforme destacam Savoia, Saito, e Santana, (2007). Ainda de acordo com os autores, após a estabilização econômica, houve o desenvolvimento do mercado financeiro, aumentando a complexidade dos produtos oferecidos e a necessidade de maior conhecimento por parte dos indivíduos para a tomada de decisões financeiras.

Tanto para Savoia et al. (2007) quanto para o Bacen (2013) e a OCDE (2004), a educação financeira é tema importante que merece destaque em decorrência da complexidade do sistema financeiro brasileiro. Os estudos brasileiros desenvolvidos na área, no entanto, ainda se mostram incipientes se comparados à amplitude que o tema possui em outros países (OCDE, 2004; Savoia et al., 2007; Bacen, 2013).

No Brasil, a educação financeira não é tema exigido pelo Ministério da Educação e Cultura (MEC). De acordo com a proposta curricular vigente, o MEC orienta para o estímulo de temas voltados para finanças, como cálculo de juros em operações financeiras, durante o ensino de Matemática (Ministério da Educação e Cultura [MEC], 2000). Nos Estados Unidos, de acordo com Bernheim, Garrett, e Maki (1997), 29 dos 50 estados e um distrito adotaram alguma forma de consumer education, em português e educação financeira, nas escolas secundárias entre 1957 e 1985. Em 14 estados houve a exigência de adoção de temas específicos, como decisão financeira do conjunto familiar, orçamento, gestão de crédito, talões de cheque e juros compostos.

Na Inglaterra, a educação financeira não é trabalhada como uma matéria isolada, no entanto, seus princípios estão presentes em algumas aulas, como Matemática e Educação Moral e Cívica (England \& Chatterjee, 2005). Segundo Savoia et al. (2007), o Brasil encontra-se em estágio inferior de desenvolvimento da educação financeira se comparado aos Estados Unidos e ao Reino Unido e, para os autores, isso se deve a aspectos históricos e culturais e à pequena participação das instituições financeiras no financiamento de projetos de educação financeira e no incentivo à poupança. 
Entre os estudos sobre o tema realizados nos âmbitos nacional e internacional, pode-se citar os trabalhos de Peng, Bartholomae, Fox, e Cravener (2007), Amadeu (2009), Claudino, Nunes e Silva (2009), Vieira, Bataglia, e Sereia (2011), entre outros.

Peng et al. (2007) buscaram identificar o impacto da educação financeira nos ensinos médio e superior. Os autores aplicaram um questionário a 1.039 estudantes matriculados em uma universidade localizada no Centro-Oeste dos Estados Unidos, englobando questões sobre experiência financeira, participação em educação financeira, renda e características demográficas. Os resultados permitiram inferir que não havia relação significativa entre a educação financeira no ensino médio e o conhecimento sobre investimentos. Porém, a realização de disciplinas relacionadas às finanças pessoais no ensino superior foi associada a níveis mais altos de conhecimento sobre investimentos.

Amadeu (2009) realizou um estudo com estudantes da Universidade Estadual do Norte do Paraná (UENP), no qual analisou os conhecimentos sobre educação financeira dos alunos dos Cursos de Matemática, Ciências Contábeis, Economia e Administração. Por meio dos resultados encontrados, foi possível observar que os discentes dos cursos que tinham em sua grade curricular maior carga horária de disciplinas na área financeira responderam com mais segurança às perguntas relacionadas a finanças, em comparação àqueles matriculados em cursos com menor carga horária de disciplinas similares. Diante desses resultados, Amadeu (2009) propõe a inserção da disciplina de Educação Financeira na grade curricular, como forma de preparar os estudantes para a tomada de decisões cotidianas e melhorar o desenvolvimento pessoal e profissional dos alunos.

Claudino et al. (2009) se dispuseram a estudar os servidores públicos (técnico-administrativos) da Universidade de Viçosa, analisando sua vida financeira, nível de endividamento e correlacionando tais variáveis à educação financeira. Os autores, após a aplicação de um questionário, concluíram que o conhecimento dos servidores sobre educação financeira é considerado insuficiente (desconhecimento de liquidez, taxas de cheque especial e planejamento financeiro) e que a maioria dos respondentes se encontra pouco endividada. Ademais, por meio de testes de correlação, concluiu-se que a relação entre educação financeira e endividamento evidencia que os piores níveis de dívidas estão associados a baixo conhecimento em relação à educação financeira.

Vieira et al. (2011), por fim, analisaram a tomada de decisões de estudantes matriculados em uma universidade do Paraná. Os alunos foram divididos em dois grupos: aqueles que tiveram alguma matéria na universidade relacionada a finanças - educação financeira - e aqueles que não tiveram em sua grade matéria similar, sendo os discentes do mesmo curso, porém, matriculados em semestres distintos. Os autores concluíram que os respondentes que já cursaram matérias de finanças são mais propensos ao risco se comparados aos alunos que não cursaram essas matérias. Além disso, esses estudantes possuem maior noção de segurança de ativos financeiros do que o grupo de alunos dos semestres iniciais. Em geral, concluiu-se que a formação acadêmica favorece a melhor tomada de decisões de consumo, investimento e poupança dos indivíduos. Contudo, existem outras fontes de conhecimento que são importantes, como a experiência prática e a família, que não foram analisadas na pesquisa em questão. 


\subsection{GESTÃO DAS FINANÇAS DOMÉSTICAS}

Segundo Keynes (1996), a decisão de consumir ou não está ao alcance do indivíduo e é fortemente afetada pelo agregado familiar, em pequenas ou em grandes decisões financeiras. Para Lynch et al. (2010), os consumidores devem optar, por exemplo, por casas ou hipotecas, poupar para a educação ou para a aposentadoria, usar ou não cartões de crédito, quais dívidas honrar em primeiro lugar e contratar ou não seguros. O bem-estar familiar é resultado dessas decisões de consumo.

A decisão financeira pode ser entendida como "qualquer compra", quando um consumidor realiza uma análise de preços para chegar a uma escolha. Lynch et al. (2011), no entanto, delimitam as decisões financeiras como as opções que são capazes de gerar impacto sobre o quadro financeiro do consumidor. Dessa forma, os autores ressaltam como grandes decisões financeiras a alocação de recursos em itens de valor elevado, como planos de saúde, contratação de empréstimos, realização de investimentos e aquisição de produtos financeiros complexos.

Frente a essas múltiplas opções de escolhas, o consumidor deve atentar-se para manter o domínio sobre três aspectos principais: fazer face às despesas, manter o controle de dinheiro e lidar com compromissos irregulares (Atkinson, Mckay, Kempson, \& Collard, 2006). A realização de um planejamento financeiro se mostra relevante nesse sentido. O planejamento financeiro deve ser capaz de adequar a renda familiar às necessidades domésticas, eliminar gastos supérfluos e incluir o planejamento de compras futuras, com vistas a evitar dispêndio com juros excessivos que reduzem o poder de compra do consumidor (Halles, Sokolowski, \& Hilgemberg, 2008).

Culturalmente, o planejamento financeiro é pouco adotado no Brasil. O histórico de inflação elevada e de remarcações diárias de preço fez com que os brasileiros se acostumassem a utilizar todos seus recursos ainda no começo do mês, a fim de garantir a subsistência da família por um período maior de tempo (Halles et al., 2008).

Entre os conceitos relevantes a serem tratados quando se considera o planejamento financeiro, destacam-se os seguintes, que serão abordados ao longo deste estudo: autocontrole, visão de curto prazo, preferência ao crédito, orçamento mental, gerenciamento das receitas e despesas e propensão a planejar. Em relação ao primeiro aspecto, a falta de autocontrole, cujo conceito engloba quebrar hábitos, resistir a tentações e manter a autodisciplina (Miotto, 2013), foi relacionada como um dos fatores responsáveis pelo endividamento, sendo responsável pelo descuido no orçamento, pela administração negligente dos recursos e pela falta de autodisciplina (Lunt \& Livingstone, 1991).

A preferência no tempo é o que determina a visão de curto ou longo prazo dos planejamentos (Moura, 2005). Foi observada, entre os indivíduos endividados, uma maior preferência à obtenção de crédito para o atendimento dos desejos ou necessidades do momento do que um esforço para a construção de reserva e aquisição de tais bens no futuro (Livingstone \& Lunt, 1992). No que se refere à preferência ao crédito, o acesso a ele tem sido facilitado pelas medidas governamentais desde 2003, em razão das políticas de redução das taxas de juros e de incentivo ao crédito. Em 
decorrência disso, o estudo de Bortoluzzi et al. (2015) apontou para um aumento no endividamento dos brasileiros de 2011 a 2014, sendo o crédito pessoal e o financiamento imobiliário as principais linhas de crédito utilizadas.

A prática do orçamento mental consiste na divisão estruturada mentalmente dos recursos e dos gastos em categorias, de forma a planejar e controlar o orçamento familiar (Heath \& Soll, 1996). Quanto ao gerenciamento das receitas e despesas, nota-se que famílias com rendas mais baixas têm parte substancial do seu orçamento comprometido com despesas essenciais, o que aumenta a importância da gestão de finanças e a formação de reserva nesse segmento (Miotto, 2013). Em um estudo realizado por Halles et al. (2008), por exemplo, os autores verificaram que a principal dificuldade econômica encontrada pelos servidores do Corpo de Bombeiros e da Policia Civil de Ponta Grossa era formar reservas para situações imprevistas ou para a aquisição de bens maiores. Mais de $58 \%$ dos respondentes afirmaram que utilizavam empréstimos nessas situações, o que os colocava em condições de maior dificuldade financeira. Os servidores informaram, ainda, que a inexistência de um orçamento tornava o planejamento e o controle das finanças mais difícil, e quando o orçamento era feito, o seu controle não era eficiente.

Finalmente, no que se refere à propensão a planejar, Lynch et al. (2010) ressaltam que cada indivíduo possui uma forma de planejar, e as diferenças individuais entre os planejamentos é que afetarão o bem-estar dos consumidores de variadas maneiras. Giareta (2011) relaciona o planejamento financeiro pessoal e familiar com a pirâmide das necessidades de Maslow. Para a autora, a realização de um planejamento das contas pessoais e familiares pode ser o caminho mais curto entre as necessidades fisiológicas (base da pirâmide), que incluem alimentação e moradia, até autorrealização (cume da pirâmide), que contempla a realização dos desejos pessoais.

O planejamento financeiro auxilia na formação de reservas para a realização de objetivos futuros, de médio e longo prazos, que se situam em patamares mais elevados da pirâmide de Maslow. Além disso, o planejamento é importante para garantir o conforto financeiro e a manutenção das necessidades fisiológicas frente às adversidades que podem ocorrer no curto prazo, como desemprego (Giareta, 2011).

\section{METODOLOGIA}

Esta pesquisa, por questões de acessibilidade, foi realizada com alunos do Curso de Ciências Contábeis da UFMG, selecionados entre os diversos períodos do estágio de graduação. O intuito com esta amostra foi verificar as decisões de consumo, a gestão de receitas e despesas e a tendência à poupança ou inadimplência de futuros profissionais da área de Contabilidade e Finanças.

Os dados para análise foram obtidos por meio da aplicação de questionários impressos em parte da comunidade acadêmica de Ciências Contábeis da UFMG. Foi utilizado como base um questionário já validado sobre decisões de consumo e planejamento financeiro, sendo necessárias pequenas adaptações para o alcance completo dos objetivos com este estudo. 


\subsection{ANÁLISE DE DADOS}

Após a aplicação do instrumento de pesquisa, foi realizada a tabulação dos dados, separando as respostas obtidas em cada questão. Ao todo, foram analisados 104 questionários, sendo excluídos os preenchidos parcialmente.

Os dados obtidos foram estudados utilizando, inicialmente, a análise fatorial. As questões que envolviam características pessoais foram sistematizadas em seis escores que representam a ideia predominante dessas questões: autocontrole, orçamento mental, gerenciamento de receitas e despesas, propensão a planejar, preferência ao crédito e visão de curto prazo.

A idade dos estudantes pesquisados foi relacionada aos escores obtidos anteriormente para as características pessoais por meio do teste de correlação de Spearman. Para as características sociodemográficas categóricas, foi utilizado o teste de Kruskal-Wallis. Todas as verificações ocorreram como auxílio do software Stata.

\subsection{MÉTODO}

Nesta seção apresenta-se um descritivo e uma explanação dos testes estatísticos que foram utilizados nesta pesquisa. Em síntese, foi realizada a análise fatorial, além do teste de correlação de Spearman e do teste de Kruskal-Wallis para as variáveis categóricas. Conforme Fávero, Belfiore, Silva, e Chan (2009), a análise fatorial tem o intuito de sistematizar dados inter-relacionados, gerando fatores que os representam e expressam as relações antes observadas individualmente nas variáveis correlacionadas.

Inicialmente, agruparam-se variáveis que expressam ideias comuns nos seguintes fatores: autocontrole, visão de curto prazo, preferência ao crédito, orçamento mental, gerenciamento das receitas e despesas e propensão a planejar. Tal medida reduz a possibilidade de multicolinearidade, tendo em vista que a quantidade de variáveis é reduzida.

Foi realizado o teste de normalidade dos dados de Shapiro Francia, comprovando-se a anormalidade deles. Em decorrência disso, não foi possível a utilização de um teste paramétrico, como Pearson, optando-se pelo teste não paramétrico de correlação de Spearman. Esse último trata-se de um teste não paramétrico que busca determinar o grau de associação entre duas variáveis, assim como a relação entre elas. A associação pode ser positiva se o crescimento ou o decrescimento de uma das variáveis implica a mesma ação na outra variável, ou negativa se o crescimento de uma variável implica decrescimento da outra (Triola, 2005).

Quando a hipótese nula de normalidade dos dados foi rejeitada, na comparação entre duas ou mais categorias, procedeu-se com testes não paramétricos. O teste de Mann-Whitney é um teste de amostras independentes, não paramétrico, utilizado para verificar se duas amostras distintas foram retiradas de populações com a mesma média. Como foi comprovada anormalidade dos dados da amostra, utilizou-se o teste de Mann-Whitney em substituição ao teste T de Student, 
que é paramétrico. Pelo teste de Mann-Whitney é formulada a hipótese nula de igualdade entre os dados e a hipótese alternativa de diferença neles.

Por sua vez, quando da presença de mais de duas categorias, procedeu-se com o teste Kruskal-Wallis, ou teste H. Referido teste não paramétrico visa comparar três ou mais amostras independentes, de tamanhos iguais ou desiguais. Para a realização do teste, é formulada uma hipótese nula de que não há diferença nos dados, e, de acordo com o nível de confiança, rejeitase ou não tal hipótese. O teste de Kruskal-Wallis não requer a normalidade da amostra e é utilizado quando os dados analisados são variáveis não categóricas, ou seja, variáveis que são medidas em escala nominal (Siegel, 1975).

\section{ANÁLISE DOS RESULTADOS}

Com o intuito de conhecer o perfil financeiro e a propensão ao endividamento ou à poupança dos estudantes de Ciências Contábeis da Universidade Federal de Minas Gerais, foi realizada a aplicação de 107 questionários a alunos de diversos períodos do referido Curso. Foram descartados três questionários por não estarem preenchidos integralmente, chegando-se a uma base de 104 respostas para cada pergunta.

A idade média da amostra foi de 25,5 anos, tendo respondentes de 20 a 51 anos. A maior frequência observada foi de 22 anos. A diferença na idade dos indivíduos da amostra provoca variação nas respostas em razão das experiências e estágios no ciclo de vida. De acordo com a teoria do ciclo de vida explicada por Neri, Carvalho, e Nascimento (1999), toda a amostra observada se encontra na fase de realizar poupança para garantir uma aposentadoria mais tranquila, podendo os mais jovens se endividarem para suavizar o padrão de consumo, por estarem adentrando no mercado de trabalho e possuírem menores salários.

Na Tabela 1, evidencia-se a estatística descritiva referente à idade dos indivíduos analisados:

Tabela 1

Idade dos alunos pesquisados

\begin{tabular}{ll}
\hline Média & 25,53846154 \\
Erro padrão & 0,553676536 \\
Mediana & 24 \\
Modo & 22 \\
Desvio padrão & 5,646414924 \\
Variância da amostra & 31,88200149 \\
Mínimo & 20 \\
Máximo & 51 \\
\hline
\end{tabular}

Em relação à formação acadêmica, $20 \%$ da amostra já possui curso superior completo, um resultado significativo, tendo-se por base que a média de idade dos alunos foi de 25,5 anos. Os outros $80 \%$ estão cursando a primeira graduação. Ainda em relação ao perfil sociodemográfico da amostra, 8 dos 104 pesquisados moram sozinhos, mas, em média, o núcleo familiar da amostra é composto de 3 a 4 pessoas $(3,5)$. Em relação à quantidade de indivíduos que contribuem para a renda familiar, o resultado se aproximou de $2(2,3)$, o que demonstra que na maioria das famílias dos 
alunos existe a presença de dependentes econômicos. Verificou-se, também, que a maioria dos estudantes não possui filhos (92\%) e reside em casa própria (79\%).

Dos pesquisados, $70 \%$ informaram que contribuem com a renda familiar, os outros $30 \%$ são dependentes econômicos da família, por não auferirem renda ou pela renda se destinar exclusivamente aos seus gastos pessoais. Em relação à renda familiar total, $47 \%$ dos respondentes declararam que a soma da renda de todos os integrantes ultrapassa $R \$ 5.200,00$, enquanto $32 \%$ informaram que a renda está na faixa de $R \$ 3.000,00$ a $R \$ 5.200,00$, e $18 \%$ afirmaram que o total familiar é de $R \$ 1.200,00$ a $R \$ 3.000,00$. Por fim, 3\% dos alunos declararam que a renda da família é de até $R \$ 1.200,00$, conforme se observa na Figura 1:

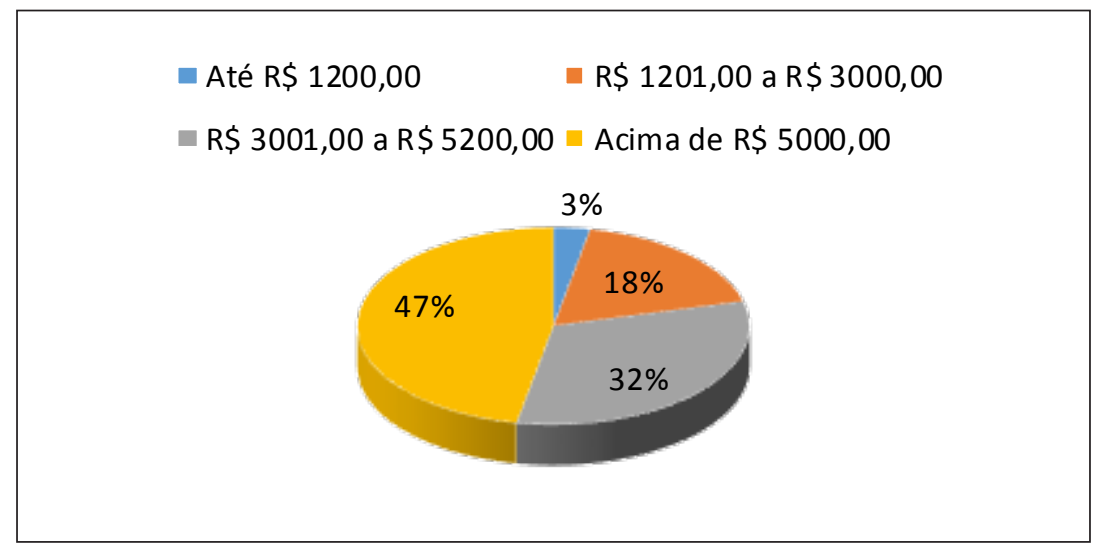

Figura 1. Renda familiar dos estudantes

Dos 104 pesquisados, 7 afirmaram nunca ter feito compra a prazo (6,7\%). A maior parte dos respondentes (43\%) informou que a última compra a prazo realizada foi com roupas e acessórios pessoais, enquanto 19\% afirmaram que o gasto se destinou à aquisição de roupas e acessórios para a família. Segundo Raghubir e Srivastava (2008), as compras a prazo podem facilitar o gasto por não gerarem nos indivíduos a sensação de saída de recursos.

Em relação à última compra a prazo, 2\% dos alunos afirmaram que o gasto foi com alimentos, o que vai em direção contrária ao bom parcelamento proposto por Macedo (2010). Segundo o autor, as compras prioritárias mensais não devem ser parceladas, pois são recorrentes, e, dessa forma, os parcelamentos não cessarão. Outros $2 \%$ informaram que a última compra a prazo foi de cosméticos, e $27 \%$ informaram outros bens, como aquisição de veículos, passagens aéreas e cursos de inglês. Tal cenário se encontra detalhado na Figura 2: 


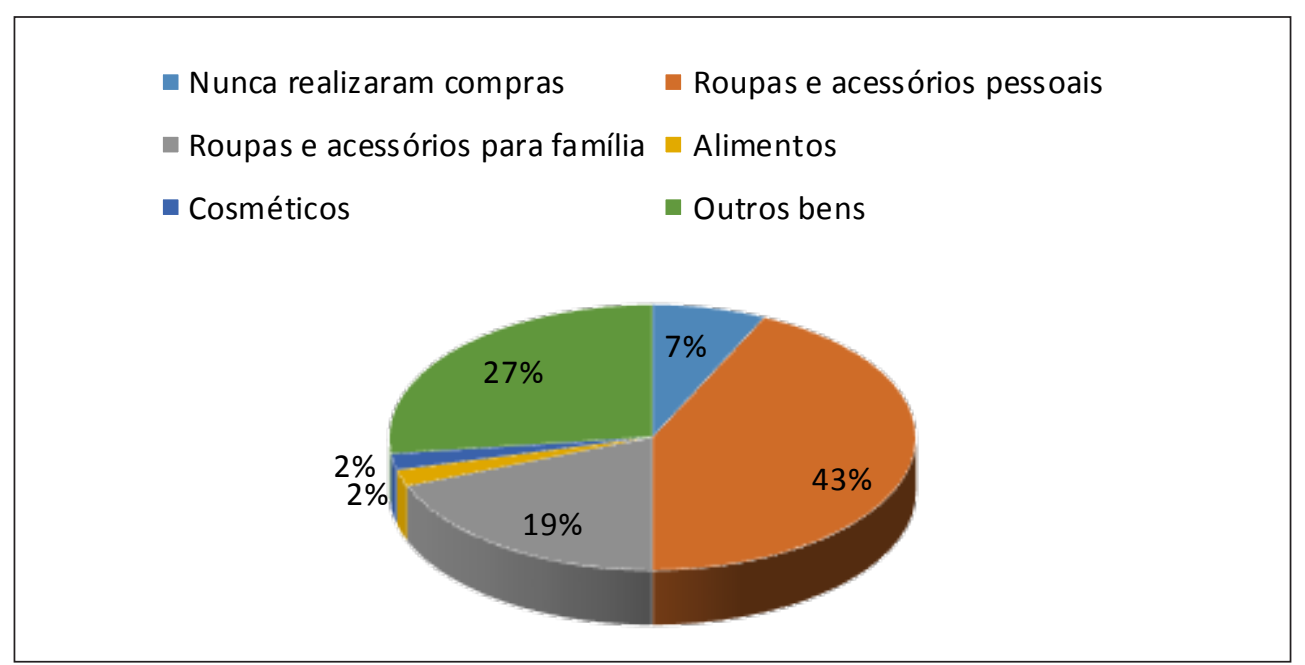

Figura 2. Destinação da última compra a prazo

Foi aplicada a análise fatorial para agregar várias questões em um fator único. Primeiramente, aplicou-se o teste de normalidade multivariada de Doornik-Hansen e a hipótese nula de normalidade dos dados foi rejeitada. Contudo, autores como Fabrigar, Maccallum, Werger, e Strahan (1999) defendem que o fato do não atendimento da normalidade multivariada para o método de fatores principais tende a não gerar grandes distorções. Assim, foi dada continuidade ao teste mesmo sem a comprovação da normalidade.

A análise fatorial foi utilizada para englobar, em apenas um fator, algumas questões do questionário relacionadas ao gerenciamento de receitas e despesas. São elas:

\begin{tabular}{|l|}
\hline Eu gerencio minhas contas de uma forma muito organizada. \\
\hline Eu sou muito impulsiva e sou tentada a comprar coisas mesmo quando, na verdade, eu não tenho dinheiro para isso. \\
\hline Eu sempre pago minhas contas em dia. \\
\hline Antes de chegar a conta do cartão de crédito eu já sei quanto vou pagar. \\
\hline
\end{tabular}

Figura 3. Escala para gerenciamento de receitas e despesas. Adaptada de "Antecedentes e consequências da gestão das finanças domésticas: uma investigação com consumidoras da classe C," de A. P. Miotto, 2013, Fundação Getúlio Vargas, São Paulo (Tese de Doutorado).

O teste Kaiser-Meyer-Olkin (KMO), utilizado para medir se a amostra é adequada, apresentou o resultado de 0,6319, o que indica uma boa resposta. Pelo teste de Bartlett (factortest), concluise que a análise fatorial é válida, pois se rejeita a hipótese nula $(p<0,05)$ de que a técnica não é adequada. É possível observar, ainda, que os sinais condizem com o esperado para o gerenciamento de receitas e despesas: "gerencio contas", "pago as contas em dia" e "sei a fatura do cartão antes mesmo de ela chegar" apresentaram relação positiva com o "gerenciamento de receitas e despesas", enquanto "ser impulsivo" demonstrou uma relação contrária.

A visão de curto prazo dos alunos, caracterizada pelo pensamento imediatista, foi analisada com base nas questões elencadas na sequência: 


\begin{tabular}{|l|}
\hline Eu penso apenas no curto prazo. \\
\hline Não me preocupo com o futuro. \\
\hline Eu vivo mais para o dia de hoje do que para o dia de amanhã. \\
\hline Minha comodidade é muito importante quando vou tomar decisões. \\
\hline
\end{tabular}

Figura 4. Escala para visão de curto prazo. Adaptada de "Antecedentes e consequências da gestão das finanças domésticas: uma investigação com consumidoras da classe C," de A. P. Miotto, 2013, Fundação Getúlio Vargas, São Paulo (Tese de Doutorado).

De acordo com a análise fatorial, observa-se a geração de dois fatores. Contudo, como o primeiro fator explicitou a variabilidade de $44,91 \%$ dos dados e este foi o único que apresentou sinais condizentes, optou-se pela utilização de um único fator. O resultado do teste KMO obtido foi de 0,5019, abaixo daquele classificado como bom, que seria de 0,6 a 0,7. No entanto, de acordo com Costa, Souza, e Gouvêa (2007), valores entre 0,5 e 1 indicam que a análise é apropriada, enquanto valores abaixo de 0,5 podem significar uma análise inadequada. Aplicando o teste de Bartlett, foi obtido um valor p menor do que 0,05, o que indica que a hipótese nula de que a análise fatorial não é adequada é rejeitada ao nível de significância de $5 \%$.

A prática do orçamento mental, conforme os estudos de Thaler (1985) e Heath e Soll (1996), foi observada junto aos estudantes de Ciências Contábeis por meio das questões reproduzidas na Figura 5:

\begin{tabular}{l}
\hline Eu costumo reservar dinheiro (do orçamento) para despesas, como alimentação, vestuário, transporte, etc. \\
\hline Eu nunca gasto mais do que eu planejei em alimentação, vestuário, transporte, etc. \\
\hline Se eu gasto mais do que eu planejei em uma coisa, eu economizo em outros gastos. \\
\hline Se num mês eu gasto mais do que o normal em uma coisa, eu gasto menos em outras coisas. \\
Figura 5. Escala para orçamento mental. Adaptada de "Antecedentes e consequências da gestão das finanças \\
domésticas: uma investigação com consumidoras da classe C," de A. P. Miotto, 2013, Fundação Getúlio Vargas, São Paulo \\
(Tese de Doutorado).
\end{tabular}

Por meio da análise fatorial, observou-se que a relação das variáveis com o fator principal gerado condiz com o esperado para a prática de orçamento mental: todas as frases mostram uma relação positiva com essa prática. O fator 1 explica $57,41 \%$ da realização do orçamento mental. Além disso, o resultado do teste KMO é 0,6834, o que indica um bom valor para a amostra. Pelo teste de Bartlett, rejeita-se a hipótese nula de que a análise fatorial não é adequada $(p<0,05)$ e, dessa forma, pode-se utilizá-la.

A preferência ao crédito é um fator importante na ocorrência de endividamento e, seu oposto, no surgimento de poupança. Dessa forma, nas questões aplicadas aos estudantes foram incluídas três alternativas voltadas ao tema:

\footnotetext{
É melhor primeiro juntar dinheiro e só depois gastar.

Prefiro comprar parcelado do que esperar ter dinheiro para comprar à vista.

Prefiro pagar parcelado mesmo que no total seja mais caro.

Figura 6. Escala para preferência ao crédito. Adaptada de "Antecedentes e consequências da gestão das finanças domésticas: uma investigação com consumidoras da classe C," de A. P. Miotto, 2013, Fundação Getúlio Vargas, São Paulo (Tese de Doutorado).
} 
A análise fatorial das questões referentes à preferência de crédito foi significativa. O resultado do teste KMO é de 0,5975, acima do 0,5 proposto por Costa et al. (2007), indicando uma análise adequada. Além disso, por meio do teste de Bartlett, tem-se que $p<0,5$, rejeitando-se a hipótese nula de que a análise fatorial não é adequada.

Os sinais condizentes "preferir comprar parcelado do que esperar ter dinheiro para comprar à vista" e "preferir comprar parcelado mesmo que seja mais caro" são preferências de quem está mais propenso ao crédito. De forma contrária a esse pensamento está: "é melhor juntar dinheiro e só depois gastar", refletindo o sinal negativo. O fator 1 explica $61,66 \%$ da realização do orçamento mental. A propensão dos alunos em realizar planejamentos foi testada mediante seis questões, listadas na Figura 7:

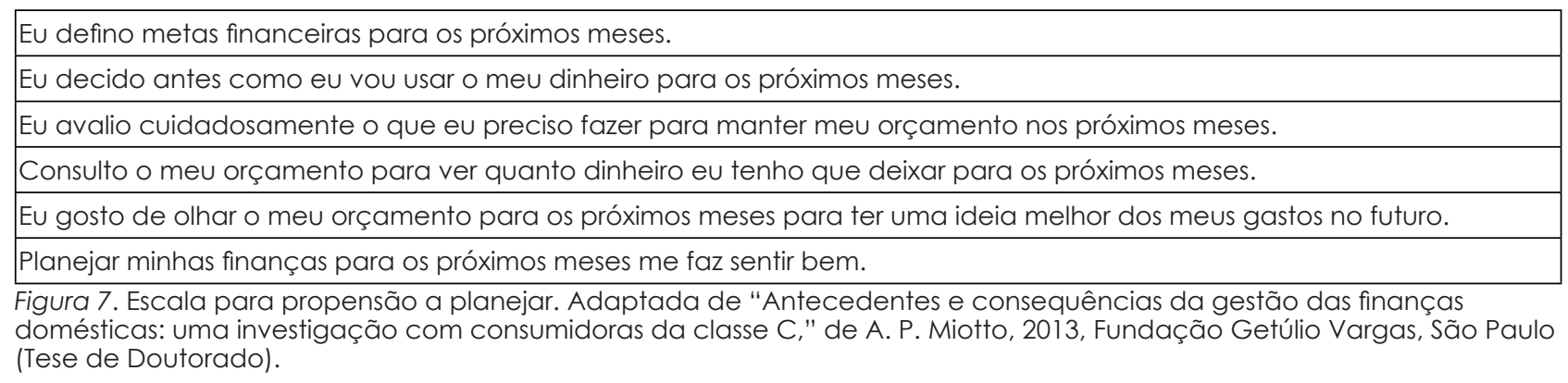

O resultado do teste KMO foi de 0,8692 , indicando um ótimo valor para a amostra. Pelo teste de Bartlett, rejeita-se a hipótese nula de que a análise fatorial não é adequada. A análise é significativa para o fator 1, que tem significativo poder de explicação do modelo (78\%). A análise de sinais condiz com o esperado para a propensão a planejar: todas as frases mostram uma relação positiva com essa prática.

Para o estudo da presença do autocontrole nos estudantes de Ciências Contábeis foram utilizadas diversas questões, descritas na Figura 8:

\begin{tabular}{|l|}
\hline Eu sou bom em resistir à tentação. \\
\hline Eu tenho dificuldade em quebrar hábitos ruins. \\
\hline Eu sou preguiçoso. \\
\hline Eu digo coisas que não deveria. \\
\hline Eu faço certas coisas que são ruins para mim, se elas são divertidas. \\
\hline Me nego a fazer coisas que são ruins para mim. \\
\hline Eu gostaria de ter mais autodisciplina. \\
\hline Prazer e diversão às vezes me impedem de fazer meu trabalho. \\
\hline Eu tenho dificuldade de concentração. \\
\hline Eu sou capaz de trabalhar efetivamente para objetivos de longo prazo. \\
\hline Às vezes eu não consigo parar de fazer alguma coisa, mesmo sabendo que é errado. \\
\hline Eu muitas vezes ajo sem pensar em todas as alternativas. \\
Figura 8. Escala para autocontrole. Adaptada de "Antecedentes e consequências da gestão das finanças domésticas: \\
uma investigação com consumidoras da classe C," de A. P. Miotto, 2013, Fundação Getúlio Vargas, São Paulo (Tese de \\
Doutorado).
\end{tabular}


Para avaliar a adequação da análise fatorial, realizou-se o teste KMO, que apresentou um ótimo valor para a análise $(0,7638)$, evidenciando que a amostra está adequada. Além disso, o teste de Bartlett rejeitou a hipótese nula de que a análise fatorial não é adequada ao nível de 5\%.

A análise fatorial das variáveis relativas ao autocontrole apresentou apenas um fator com valor superior a 1 (eigenvalue = 3,20912). Os sinais das proposições estão coerentes com a literatura, pois "eu sou bom em resistir à tentação", "me nego a fazer coisas que sejam ruins para mim" e "eu sou capaz de trabalhar efetivamente para objetivos de longo prazo" apresentam ideias opostas às demais.

Após a análise fatorial, foram obtidos resultados e correlações que permitiram analisar o comportamento financeiro geral dos estudantes de Ciências Contábeis da UFMG, bem como a relação entre a ocorrência de poupança ou endividamento e as características sociodemográficas apresentadas. Foi realizado um comparativo entre os resultados obtidos nesta pesquisa e os de outros estudos divulgados acerca das decisões de consumo de variados segmentos da população brasileira.

Analisou-se a correlação entre as variáveis sistematizadas por meio da análise fatorial. Como o teste Shapiro Francia verificou que os dados não apresentam normalidade, foi utilizada a correlação de Spearman para a análise (Tabela 2). Os resultados evidenciam uma relação já esperada e condizente com os estudos de Miotto (2013). O gerenciamento de receitas e despesas, o orçamento mental e a propensão a planejar se correlacionaram positivamente e mostraram relação inversa com a preferência ao crédito e a visão de curto prazo, que são correlacionados. Conforme Lea, Webley, e Walker (1995), a preferência pelo crédito demonstra uma dificuldade na visão de longo prazo e do consumo futuro.

Tabela 2

Matriz de correlação entre as variáveis analisadas pela análise fatorial

\begin{tabular}{|c|c|c|c|c|c|c|}
\hline & Idade & Gerenc. & Orçam. mental & Pref. crédito & Prop. planejar & Visão C. prazo \\
\hline Idade & 1 & & & & & \\
\hline Gerenciamento & -0.01 & 1 & & & & \\
\hline Orçam. mental & 0.01 & $0.58^{* * *}$ & 1 & & & \\
\hline Pref. crédito & 0.03 & $-0.46^{* * *}$ & $-0.42^{* * *}$ & 1 & & \\
\hline Prop. planejar & -0.03 & $0.78^{* * *}$ & $0.52^{* * *}$ & $-0.37^{* * *}$ & 1 & \\
\hline Visão curto prazo & 0.12 & $-0.31^{* * *}$ & $-0.28 * * *$ & $0.20 * *$ & $-0.24^{* *}$ & 1 \\
\hline
\end{tabular}

A partir da análise de correlação, observou-se que a idade dos alunos não é um fator que mantém correlação com as características pessoais de gerenciamento de receitas e despesas, orçamento mental, preferência ao crédito, propensão a planejar e visão de curto prazo. Dessa forma, não foi possível identificar um padrão de comportamento por meio da análise da idade dos estudantes.

Neri et al. (1999) explicam que, segundo a teoria do ciclo da vida, os indivíduos tendem a formar poupança ao longo da vida com o intuito de conseguir manter um padrão estável de consumo durante a velhice, quando, em geral, ocorre uma redução na renda. Na etapa inicial do ciclo de vida, os indivíduos estão entrando no mercado de trabalho, mas geralmente com rendas 
mais baixas. Ocorre que, em situações em que há disponibilidade de crédito, as pessoas tendem a contrair empréstimos para suavizar o padrão de consumo, com a expectativa de ascensão profissional futura e o aumento da renda. Em situações em que os indivíduos não têm acesso ao crédito, eles permanecem restritos por liquidez (Neri et al., 1999). Dessa forma, segundo Neri et al. (1999) e Silveira e Moreira (2014), espera-se que, na juventude, a taxa de poupança seja positiva para que se possa acumular recursos para a aposentadoria. Neste estudo, porém, não se evidenciou a teoria do ciclo de vida, por não ser possível correlacionar a idade a nenhuma característica comportamental na amostra.

Os estudantes que efetuavam poupança foram questionados sobre a finalidade desses depósitos. Pelo modelo de Lindqvist (1981), a poupança poderia ser necessária para: gestão de caixa; imprevistos e emergências; alcançar objetivos financeiros; e formação de investimentos. Consequentemente, a poupança, além de ser reserva para imprevistos, também seria útil na aquisição de bens, sem necessidade de recorrer a crédito de terceiros. Neste estudo foram estipuladas três opções de respostas aos estudantes, em relação à finalidade da poupança: para situações de emergência, para aposentadoria ou para comprar algo de valor. Não foi observada, pelo teste de Kruskal-Wallis, nenhuma associação entre a finalidade para a qual os estudantes realizam poupança e as características pessoais analisadas.

Os alunos foram questionados, também, sobre a renda familiar. Por meio do teste de KruskalWallis relacionou-se cada uma das quatro faixas de renda apresentadas com as características pessoais em análise: gerenciamento de receitas e despesas, orçamento mental, propensão a planejar, preferência ao crédito e visão de curto prazo. Observou-se que apenas em relação à "preferência ao crédito" a hipótese nula de que não há diferença entre os dados foi rejeitada (valor $p<0,05)$. Fazendo-se a soma das respostas em relação à preferência ao crédito e observando-se a faixa de renda, tem-se que a faixa de renda 1 (renda familiar de até $R \$ 1.200,00$ ) é a mais propensa ao crédito. Além disso, as faixas de renda 2 e 3 (de $R \$ 1.200$ a $R \$ 5.200$ ) são pouco relacionadas ao crédito e os alunos que estão na faixa de renda mais alta (acima de $R \$ 5.200$ ) se mostraram negativamente relacionados ao crédito, ou seja, avessos a este.

Os resultados obtidos condizem com os estudos nessa área. Conforme Miotto (2013), as rendas mais baixas possuem maior parte do orçamento comprometido com gastos essenciais, o que faz com que o esforço para a realização de poupança seja maior, assim como a necessidade do planejamento financeiro. Katona (1975) também identifica a baixa renda como uma das causas do endividamento. De forma análoga, tem-se os estudantes inseridos em famílias com renda acima de $R \$ 5.200$, que possuem, portanto, orçamentos menos restritos e que se mostram avessos ao crédito.

Buscou-se analisar, ainda, a relação entre o fato de possuir ou não filhos com as características pessoais objeto de estudo: gerenciamento de receitas e despesas, orçamento mental, propensão a planejar, preferência ao crédito e visão de curto prazo. Macedo (2010) ressalta que o costume de poupar possibilita, por exemplo, ter uma reserva para poder arcar com a educação dos filhos, portanto, esperava-se uma possível relação entre possuir ou não filhos e o comportamento dos indivíduos em relação às finanças pessoais. Foi utilizado o teste de Mann-Whitney e o valor p obtido 
nos testes não rejeitou a hipótese nula de que não há diferença nos dados para nenhum dos fatores. Não foi possível, portanto, a identificação de associação entre o fato de os alunos possuírem ou não filhos e as características pessoais mencionadas.

Por fim, o fato de possuir ou não curso superior completo também não apresentou associação com as características pessoais que foram analisadas. De acordo com o teste não paramétrico de Mann-Whitney, a hipótese nula de que não há diferença nos dados não foi rejeitada $(p>0,05)$. Ponchio (2006) relacionou, em seus estudos, uma menor escolaridade com o endividamento. Já Claudino et al. (2009), ao analisarem servidores públicos lotados na Universidade de Viçosa, concluíram que há uma relação entre educação financeira e endividamento, evidenciando que os piores níveis de dívidas estão associados a baixo conhecimento em relação à educação financeira. Vieira et al. (2011), de modo similar, ao investigarem a tomada de decisões de estudantes matriculados em uma universidade do Paraná, identificaram que a formação acadêmica favorece a melhor tomada de decisões de consumo, investimento e poupança dos indivíduos. Para os estudantes de Ciências Contábeis analisados neste estudo, no entanto, não se verificou distinção entre alunos da primeira graduação e alunos com curso superior completo.

\section{CONCLUSÃO}

Nesta pesquisa exploraram-se os antecedentes e as consequências da gestão de finanças domésticas. A princípio, foi elaborado um estudo bibliográfico sobre as características pessoais que podem influenciar na gestão financeira dos indivíduos, podendo ocasionar a poupança ou o endividamento. As características pessoais abordadas foram: autocontrole, visão de curto prazo, preferência por crédito, propensão a planejar, idade e estágio no ciclo de vida, nível de educação formal e ocorrência de eventos críticos. Em um segundo momento, buscou-se conhecer a forma como os alunos do Curso de Ciências Contábeis da UFMG lidam com suas finanças, realizando, para tal, a aplicação de questionários de cunho quantitativo. Ao todo, foram 104 questionários validados, com respostas de alunos de diversos períodos.

Os estudantes se mostraram altamente bancarizados. Dos 104 respondentes, apenas um não possui conta corrente, e, mesmo assim, possui poupança e opera com cartão de crédito. $O$ envolvimento dos alunos com o mercado financeiro reflete a inserção social e no mercado de trabalho desses estudantes, mas também requer deles um conhecimento mais apurado de finanças.

Os questionários foram analisados utilizando-se a análise fatorial, o teste de correlação e os testes não paramétricos de Kruskal-Wallis e Mann-Whitney. Não foi possível definir um perfil financeiro de acordo com a idade, pois os testes não se mostraram significativos para as variáveis em análise: gerenciamento de receitas e despesas, orçamento mental, propensão a planejar, preferência ao crédito e visão de curto prazo. É importante ressaltar, no entanto, que $89 \%$ dos alunos afirmaram possuir poupança, o que está em consonância com o pensamento de Silveira e Moreira (2014), os quais defendem que, na juventude, a taxa de poupança deve ser positiva. Em comparação com a 
população brasileira, no entanto, os dados da Confederação Nacional de Dirigentes Lojistas ("80\% dos brasileiros," 2014) mostram que a juventude é a fase em que os brasileiros estão mais endividados.

A finalidade para a qual os estudantes buscam realizar poupança também foi analisada, e, pelo teste de Kruskal-Wallis, não foi observada nenhuma associação entre esse objetivo e as características pessoais de gerenciamento de receitas e despesas, orçamento mental, propensão a planejar, preferência ao crédito e visão de curto prazo.

A maior parte dos alunos está inserida em núcleos familiares com renda superior a $R \$ 5.201$ (47\%). Esse grupo, de maior faixa de renda, apresentou aversão ao crédito. Não foi possível identificar relações desse grupo com as demais características pessoais. Os estudantes que possuem a menor renda familiar (até $R \$ 1.200$ ) se mostraram propensos ao crédito. Esse resultado é condizente com a literatura, que identifica que parte significativa do orçamento de famílias de baixa renda é comprometida com necessidades básicas e qualquer evento incerto pode gerar instabilidade econômica.

Em relação às características pessoais analisadas, o autocontrole apresentou problemas em seus resultados. A revisão das questões utilizadas e uma amostra maior poderiam viabilizar a utilização dessa variável no modelo, por reduzir a possibilidade de interpretação errônea e por minimizar o impacto de outliers nas respostas. Um estudo englobando alunos de outros cursos, também na área de ciências socioaplicadas, seria interessante por permitir uma maior amostra e a identificação de diferentes perfis por curso. A inclusão de estudantes de todos os períodos da graduação também possibilitaria verificar se há alguma modificação na forma de gerenciar as finanças de acordo com o avanço na graduação. Como sugestões para futuras pesquisas, ressalta-se, também, a inclusão da análise por gênero, com vistas a identificar se há um perfil comportamental associado a essa variável e a estimação de modelos de regressão linear múltipla, com o propósito de obter resultados mais robustos em termos das variáveis que poderiam explicar o comportamento dos estudantes, entre elas, por exemplo, o fato de o indivíduo ter tido contato com a educação financeira no ensino médio, como investigado por Peng et al. (2007).

\section{REFERÊNCIAS}

Amadeu, J. R. (2009). A educação financeira e sua influência nas decisões de consumo e investimento: Proposta de inserção da disciplina na matriz curricular (dissertação de Mestrado). Universidade do Oeste Paulista, Presidente Prudente.

Atkinson, A., Mckay, S., Kempson, E., \& Collard, S. (2006). Levels of financial capability in the UK: Results of a baseline survey. Consumer Research Report 47. London, England: Financial Services Authority.

Banco Central do Brasil. (2013). Caderno de Educação Financeira - Gestão de Finanças Pessoais (Conteúdo Básico). Retirado de https://www.bcb.gov.br/pre/pef/port/caderno_cidadania_financeira.pdf 
Bernheim, D., Garrett, D. M., \& Maki, D. M. (1997, July). Education and saving: The long term effects of high school financial curriculum mandates. National Bureau of Economic Research, 6.085.

Borges, P. R. S. (2010, outubro). Educação financeira e sua influência no comportamento do consumidor no mercado de bens e serviços. Anais do Encontro de Produção Científica e Tecnológica, Campo Mourão, PR, 5.

Bortoluzzi, D. A., Boligon, J. A. R., Hollveg, S. D. S., \& Medeiros, F. S. B. (2015). Aspectos do endividamento das famílias brasileiras no período de 2011-2014. Perspectiva, 39, 111-123.

Claudino, L. P., Nunes, M. B., \& Silva, F. C da. (2009, agosto). Finanças pessoais: Um estudo de caso com servidores públicos. Anais do Seminário em Administração, São Paulo, SP, 12. Retirado de http://sistema.semead.com.br/12semead/resultado/trabalhosPDF/724.pdf

Costa, G. G. de O., Souza, R. C., \& Gouvêa, V. H. C. (2007, Janeiro-Dezembro). Um procedimento inferencial para análise fatorial utilizando as técnicas bootstrap e jackknife: Construção de intervalos de confiança e testes de hipóteses. Rev. Univ. Rural. Sér. Ci. Exatas e da Terra, 26 (1-2), 33-44.

$80 \%$ dos brasileiros preferem o cartão na hora de parcelar, mas só um terço conhece os juros cobrados. (2014, junho). Confederação Nacional de Dirigentes Lojistas. Retirado de http://www. cndl.org.br/noticia/80-dos-brasileiros-preferem-o-cartao-na-hora-de-parcelar-mas-so-um-tercoconhece-os-juros-cobrados

England, J., \& Chatterjee, P. (2005). Financial education: A review of existing provision in the UK. Kansas: Corporate Document Services.

Fabrigar, L. R., Maccallum, R. C., Wegner, D. T., \& Strahan, E. J. (1999, September). Evaluating the use of exploratory factor analysis in psychological research. Psychological methods, 4(3), 272.

Fávero, L. P., Belfiore, P., Silva, F. D., \& Chan, B. L. (2009). Análise de dados. Modelagem multivariada para tomada de decisões. Rio de Janeiro: Campus.

Giareta, M. (2011). Planejamento financeiro pessoal: Uma proposta de controle de fluxo de caixa para orçamento familiar (monografia de Especialização). Universidade Federal do Rio Grande do Sul, Porto Alegre.

Halles, C. R., Sokolowski, R., \& Hilgemberg, E. M. (2008). O planejamento financeiro como instrumento de qualidade de vida. Anais do Seminário de Políticas Públicas no Paraná, Curitiba, PR, Brasil, 1 .

Heath, C., \& Soll, J. B. (1996, June). Mental budgeting and consumer decisions. Journal of Consumer Research, 23(1), 40-52. 
Instituto Brasileiro de Opinião Pública e Estatística. (2012, junho). Retratos da sociedade brasileira: Inclusão financeira.

Katona, G. (1975). Psychological Economics. New York: Elsevier.

Keynes, J. M. (1996). A teoria geral do emprego, do juro e da moeda. São Paulo: Nova cultural.

Lea, S. E. G., Webley, P., \& Walker, C. M. (1995, December). Psychological factors in consumer debt: Money management, economic socialization, and credit use. Journal of Economic Psychology, 16(4), 681-701.

Lindqvist, A. (1981, January). A note on determinants of household saving behavior. Journal of Economic Psychology, 1 (1), 39-57.

Livingstone, S. M., \& Lunt, P. K. (1992, March). Prediciting personal debt and debt repayment: Psychological, social and economic determinants. Journal of Economic Psychology, 13, 111-134.

Lunt, P. K., \& Livingstone, S. M. (1991, December). Psychological, social and economic determinants of saving: Comparing recurrent and total savings. Journal of Economic Psychology, 12 (4), 621$641,1991$.

Lynch, J. G. Jr., Netemeyer, R. G., Spiller, S. A., \& Zammit, A. (2010, June). A generalizable scale of propensity to plan: The long and the short of planning for time and for money. Journal of Consumer Research, 37(1), p. 108-128.

Macedo, J. S., Jr. (2010). A árvore do dinheiro: Guia para cultivar sua independência financeira. Rio de Janeiro: Elsevier.

Ministério da Educação e Cultura. (2000). Parâmetros curriculares nacionais: Ensino médio. Brasília, DF: MEC.

Miotto, A. P. (2013). Antecedentes e consequências da gestão das finanças domésticas: Uma investigação com consumidoras da classe C (tese de Doutorado). Fundação Getúlio Vargas, São Paulo.

Moura, A. G. de. (2005). Impacto dos diferentes níveis de materialismo na atitude ao endividamento e no nível de dívida para financiamento do consumo nas famílias de baixa renda do município de São Paulo (dissertação de Mestrado). Fundação Getúlio Vargas, São Paulo.

Neri, M., Carvalho, K., \& Nascimento, M. (1999). Ciclo da vida e motivações financeiras (com especial atenção aos idosos brasileiros). Rio de Janeiro: Instituto de Pesquisa Econômica Aplicada. Retirado de http://www.ipea.gov.br/portal/index.php?option=com_content\&view=article\&id=3980 
Organização de Cooperação e de Desenvolvimento Econômico. (2004). OECD's Financial Education Project. Retirado de www.oecd.org/

Peng, T. M., Bartholomae, S., Fox, J. J., \& Cravener, G. (2007, June). The impact of personal finance education delivered in high school and college courses. Journal of Family and Economic Issues, 28(2), 265-284.

Ponchio, M. C. (2006). The influence of materialism on consumption indebtedness in the context of low income consumers from the city of Sao Paulo (tese de Doutorado). Fundação Getúlio Vargas, São Paulo.

Raghubir, P., \& Srivastava, J. (2008). Monopoly money: The effect of payment coupling and form on spending behavior. Journal of Experimental Psychology: Applied, 14(3), 213-225.

Savoia, J. R. F., Saito, A. T., \& Santana, F. de A. (2007). Paradigmas da educação financeira no Brasil. Revista de Administração pública, 41 (6, ), 1121-1141.

Siegel, S. (1975). Estatística Não Paramétrica. São Paulo: McGraw-Hill do Brasil.

Silveira, M. A. C., \& Moreira, A. R. B. (2014). Taxa de poupança e consumo no ciclo da vida das familias brasileiras: evidência microeconômica. IPEA. Retirado de http://www.ipea.gov.br/portal/index.php?option=com_content\&view=article\&id=23335

Slomp, J. Z. F. (2008). Endividamento e Consumo. Revista das Relações de Consumo, 109-131.

Thaler, R. (1985, Summer). Mental accounting and consumer choice. Marketing Science, 4(3), 199214.

Triola, M. F. (2005). Introdução à estatística. Rio de Janeiro: LTC.

Vieira, S. F. A., Bataglia, R. T. M., \& Sereia, V. J. (2011). Educação financeira e decisões de consumo, investimento e poupança: Uma análise dos alunos de uma universidade pública do norte do Paraná. Revista de Administração, 9(3), 61-86.

\section{Agradecimento}

Agradecemos ao apoio do Programa Institucional de Auxílio à Pesquisa de Docentes Recém-contratados (PRPQ/UFMG). 


\section{Como citar este artigo:}

ABNT

MARQUES, Mariana Ferreira Soares; TAKAMATSU, Renata Turola; AVELINO, Bruna Camargos. Finanças pessoais: uma análise do comportamento de estudantes de Ciências Contábeis. RACE,

Revista de Administração, Contabilidade e Economia, Joaçaba: Ed. Unoesc, v. 17, n. 3, p. 819-840, set./dez. 2018. Disponível em: <http://editora.unoesc.edu.br/index.php/race>. Acesso em: dia/ mês/ano.

APA

Marques, M. F. S., Takamatsu, R. T., \& Avelino, B. C. (2018). Finanças pessoais: Uma análise do comportamento de estudantes de Ciências Contábeis. RACE, Revista de Administração, Contabilidade e Economia, 17(3), 819-840. Retirado de http://editora.unoesc.edu.br/index.php/race 
